\title{
The impact of a changed legislation on reporting of adverse drug reactions in Sweden, with focus on nurses reporting
}

Sofia A. Karlsson, Ingela Jacobsson, Marit Danell Boman, Katja M. Hakkarainen, Henrik Lövborg, Staffan Hägg and Anna K Jönsson

\section{Linköping University Post Print}

\section{Tweet}

N.B.: When citing this work, cite the original article.

The original publication is available at www.springerlink.com:

Sofia A. Karlsson, Ingela Jacobsson, Marit Danell Boman, Katja M. Hakkarainen, Henrik Lövborg, Staffan Hägg and Anna K Jönsson, The impact of a changed legislation on reporting of adverse drug reactions in Sweden, with focus on nurses reporting, 2015, European Journal of Clinical Pharmacology, (71), 5, 631-636.

http://dx.doi.org/10.1007/s00228-015-1839-6

Copyright: Springer Verlag (Germany)

http://www.springerlink.com/?MUD=MP

Postprint available at: Linköping University Electronic Press

http://urn.kb.se/resolve?urn=urn:nbn:se:liu:diva-118037 


\section{The impact of a changed legislation on reporting of adverse drug}

\section{reactions in Sweden, with focus on nurses' reporting}

Sofia A Karlsson ${ }^{1}$, Ingela Jacobsson ${ }^{2}$, Marit Danell Boman ${ }^{3}$, Katja M Hakkarainen ${ }^{4,5}$, Henrik Lövborg $^{2}$, Staffan Hägg ${ }^{2,5}$, Anna K Jönsson ${ }^{2}$

Affiliations:

1. Department of Public Health and Community Medicine, the Sahlgrenska Academy at University of Gothenburg, Gothenburg, Sweden

2. Department of Clinical Pharmacology and Department of Medical and Health Sciences, Linköping University, Linköping, Sweden

3. Division of Clinical Pharmacology, University Hospital of Umeå, Umeå, Sweden

4. Nordic School of Public Health NHV, Gothenburg, Sweden

5. Futurum - Academy for Health and Care, Jönköping County Council, Jönköping, Sweden

Corresponding author:

Anna K Jönsson

Address: Department of Clinical Pharmacology and Department of Medical and Health

Sciences, Linköping University, SE-581 83 Linköping, Sweden

E-mail: anna.k.jonsson@lio.se

Phone: +46101037420

Fax number: +46 31104195 


\section{Abstract}

Purpose: In March 2007, a legislative amendment was issued in Sweden compelling nurses to report; which included all nurses as reporters ofall suspected adverse drug reactions (ADRs) to the national pharmacovigilance system. The aim of this study $\underline{\text { is }}$ was to describe the status of ADR reporting in Sweden, before and after the implementation of the legislative changes in the legislation and to describe the general characteristics of the suspected ADRs reported by nurses.

Methods: The $\underline{\text { Swedish }}$ pharmacovigilance system in Sweden-during the study period constituted of six regional centres that, which handledresponsible for the handling of all spontaneous ADR reports within their region. In this study we identified all individual ADR reports from 2005 and 2010-were identified, reports from, analysed in depth the ADR reports from two regional centres-were serutinised, and collated information about the reporter and the nature of the reported ADR was analysed.

Results: From the two regional centres, a total of In total-898 reports were submitted in 2005 and 1074 reports in 2010 were submitted in 2005 and 2010 respectively. Nurses submitted $31 \%$ (275 reports) of the reports in 2005 and 24\% (260 reports) in 2010. Reperting frem nursesNurses' reporting of serious ADRs was 3\% (7 reports) in 2005 and 7\% (17 reports) in 2010 and-with reporting of unlabelled ADRs wasat 4\% (11 reports) in 2005 and 17\% (45 reports) in 2010. Most of the serious and/or unlabelled reactions were related to vaccine administration $s$ (14 reports in 2005 and 36 reports in 2010).

Conclusions: The overall ADR reporting by nurses after the legislative amendment did not appear to increase after the change in thereporting legislation. The proportion of serious and/or unlabelled ADR reperts fremreported by nurses did however appear to increase during the same period. Taken together our data suggests that fFurther pro-active measures actions should be considered in order to involve nurses in nurses more effectively in the reporting of 
suspected ADRs.

Keywords: adverse drug reaction, spontaneous reporting, pharmacovigilance, nurses. 


\section{Introduction}

Adverse drug reactions (ADRs) are one of the most common causes of morbidity and mortality and constitute a major problem both in medical and economical terms [1-5]. Post marketing, spontaneous reporting of suspected ADRs is an essential part of an effective pharmacovigilance systems. The goal of ADR reporting systems is_to increase patient safety by collecting information about suspected ADRs in order to detect previously unknown ADRs or obtain new information on known ADRs. Underreporting is however a major challenge prolonging the time to identify new informationin the identification and

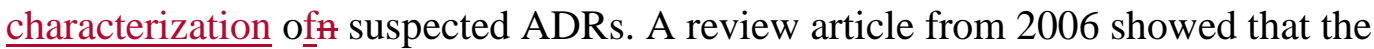
underreporting is a serious problem with reporting rates of reporting-varying ied from between 0 and $94 \%$, with an overall average reportting rate of $6 \%$ [6]. Several reasons for the One reason underreporting of ADRs have been suggested including why only a small proportion of ADRs are reported a has been discussed, such as is-lack of knowledge on how to report ADRs, misconception that absolute confidence in the diagnosis of an ADR is necessary and lack of time among healthcare professionals [7].

In Sweden, reporting of suspected ADRs has been mandatory since 1975 for physicians, dentists, and nurses with prescription privileges [8]. Nurses in particular-have close contact with patients and they are eømmonly generally responsible for the administration of drug therapy in inpatientshospitalised patientscases patients. As a result of their role in patient care, nurses have the potential to play a valuable role in the enhancement ofing pharmacovigilance systems. Previous studies on ADR reporting have shown that the quantity, quality and information gained from ADR reports is markedly increased if nurses are included in the reporting system by nurses have shown that the reporting rate increases if nurses are included as reporters of suspected ADRs-[8-11], the quality of the reported ADRs 
reporting has been shown to be adequate and their reports contribute with new information

\section{$[12,13]$. In Sweden, reporting of suspected ADRs has been mandatory since 1975 for}

physicians, dentists, and nurses with prescription privileges [14]. Among nurses with prescription privileges in Sweden, the proportion of nurses reporting ADRs has increased from $2-3 \%$ in the 1990 s to $12 \%$ in 2004 [11]. In order to increase the overall reporting of ADRs, a legislative amendment was issued in Sweden in March 2007, where all nurses were included as reporters of suspected ADRs [15]. The effects of the new legislation on suspected ADR reporting has $v e$, however, not been evaluated. The aim of this study was therefore to describe_the-ADR reporting from healthcare professionals in Sweden, before and after the change in the legislation and to describe the characteristics of the reported-suspected_ADRs by nurses.

\section{Methods}

Since 1965 Sweden has a spontaneous reporting system for suspected ADRs. Until 2012 the Pharmacovigilance system in Sweden consisted of six regional centres, which handled the spontaneous ADR reports within their region. Within the Pharmacovigilance system all suspected serious, uncommon or otherwise unexpected ADRs were supposed to be reported. Moreover, reporting of all ADRs was encouraged during the first 2 years after drug approval. Information from each individual report was stored in the national database; the Swedish Drug Information System (SWEDIS). Data stored in the database consisted of information about the patient, drugs used, suspected ADRs, outcome, causality assessment, the reporter, origin of the report and administrative data. Until 2012 the WHO definition of an $\mathrm{ADR}_{2}$ "a response to a drug which is noxious and unintended, and which occurs at doses normally used in man for the prophylaxis, diagnosis,-or therapy of disease, or for the modification of physiological function”, was used within the Swedish spontaneous reporting system [16]. 
In SWEDIS drugs can be listed as being suspected of having caused or contributed to the reaction, as interacting with another prescribed drug, or as concomitant medication not related to the ADR. Drugs were coded according to the WHO Collaborating Centre for Drug Statistics Methodology International Anatomical Therapeutic Chemical (ATC) classification [17]. The ADRs were classified according to the Medical Dictionary for Regulatory Activities (MedDRA) terminology [18]. Each report may include more than one ADR and/or drug. Each ADR was classified with respect to its causality using the WHO definitions [16]; Certain: plausible time relationship to drug exposure, positive de and rechallenge. Probable: reasonable time sequence to drug exposure, positive dechallenge, other explanations are unlikely. Possible: reasonable time sequence to drug exposure, dechallenge may be lacking other possible explanations may exists. Unlikely: unreasonable time sequence to drug exposure and other plausible explanations exists. Unclassified: more data are essential for a proper assessment or additional data are being examined. Unclassifiable: insufficient or contradictory information that cannot be supplemented or verified. Moreover, each ADR was elassified as serious if leading to death, required hospital admission or prolongation of existing hospital stay, results in persistent or significant disability/incapacity, or is life threatening and not serious if the reaction was transient and managed without the need for hospitalizationand seriousness [19]. The reported ADRs were classified as unlabelled if the reported reactions were not included in the ADR section of the Summary of Product Characteristics (SPC) at the time when the ADR was reported.

All individual ADR reports from 1st of January to 31st of December of 2005 and 2010 were identified in SWEDIS. The ADR reports from the Southeast regional Pharmacovigilance centre and the Northern regional Pharmacovigilance centre in Sweden were collected and 
scrutinised. The population living in the two regions comprised 21\% (1,860, 582 individuals) in 2005 and 20\% (1,877,255 individuals) in 2010 of the Swedish population and included a population with similar age and gender distribution as Sweden in total [20]. was. Information on the reporter (age, sex and profession) and the reported ADR (MedDRA classification, administered drugs, seriousness, labelling in the SPC and causality assessment) were extracted from the ADR reports. Reporters were categorized as nurse (working in primary care, in hospital or in school healthcare), physician (working in primary care or in hospital) and other (dentist). The category other also included reports submitted from other healthcare professionals not obligated to report ADRs, including reports from dental hygienists, pharmacists and laboratory technicians.- Information about the physicians' level of education, medical specialists training were identified in a register of all physicians in Sweden.

The data were analysed descriptively. For each reporter category (physician, nurse and other), the proportions of reported ADRs, serious and/or unlabelled ADRs were calculated. MoreoverFurthermore, serious and/or unlabelled ADRs reported by nurses were described in more detail.

\section{Results}

In total 4065 reports were submitted to the Swedish pharmacovigilance system in 2005 and 5159 reports in 2010. Of these 22\% (898 reports) in 2005 and 21\% (1074 reports) in 2010 were submitted to the Northern and the Southeast regional pharmacovigilance centres. Most of the reporters were physicians (67\% in 2005 and 75\% in 2010), and -female (58\% in 2005 and 60\% in 2010) (table 1). Among nurses 98\% were female in 2005 and $93 \%$ in 2010. 
The proportion of reports submitted by nurses was 31\% in 2005 (275 reports) and 24\% (260 reports) in 2010. The proportion of reports from hospital nurses was $0.4 \%$ (4 reports) in 2005 and 2\% (25 reports) in 2010 and from nurses in primary care 6\% (55-57 reports) in 2005 and $9 \%$ (96 reports) in 2010. The proportion of reports from nurses working in the school healthcare in the Northern regional Pharmacovigilance Centre was 14\% (46 reports) in 2005 and 12\% (49 reports) in 2010. In the Southeast regional Pharmacovigilance centre 30\% (168 reports) of the reports was from nurses working in the school healthcare in 2005 compared with $13 \%$ (88 reports) in 2010. In 2005100 reporters submitted more than 1 report compared to 172 reporters in 2010.

The majority of the reported ADRs were non-serious (66\% in 2005 and 61\% in 2010) and labelled reactions (76\% in 2005 and $74 \%$ in 2010) that had at least a possible causal relationship to the suspected drug(s) (table 2). The reporting of unlabelled ADRs among nurses was 4\% in 2005 and $17.3 \%$ in 2010, and among physicians 32\% in 2005 and $29 \%$ in 2010. The reporting of serious reactions among nurses was $3 \%$ in 2005 and $7 \%$ in 2010, and among physicians 48\% in 2005 and $49 \%$ in 2010.

The majority of substances reported by nurses as suspected to have caused an ADR were anti-infectives for systemic use (such as antibiotics, vaccines and antivirals) 95\% (262 reports) in 2005. Although reports containing anti-infectives for systemic use appeared to decrease in 2010 among nurses, this category still accounted for more than $80 \%$ (231 reports) of all reports. Vaccines accounted for most of these reports. Vaccines also constituted the largest drug group that was assessed as causing serious and/or unlabelled ADRs reported by nurses in 2005 and 2010 (table 3). In 2010, the spectrum of suspected drugs among serious 
and/or unlabelled ADRs also included reports from e.g. anti-bacterials, nervous system drugs, contrast media and drugs for treatment of bone disease and obstructive airways.

\section{Discussion}

This retrospective study indicates that the proportion of adverse drug reactionsADRs reported by nurses in the Southeast and Northern Pharmacovigilance Centres in Sweden did not increase after the legislative amendment that included all nurses as reporters of suspected ADRs. There did however appearedhowever appear to be an increase in reports from nurses working outside the school healthcare and in. $\mathrm{T}$ the proportion of serious and/or unlabelled ADRs from nurses in general. did however appear to increase This, suggestsing a shift after the legislative amendment towards nurses reporting more ADRs that add new information within the Pharmacovigilance system-after the legislative amendment.

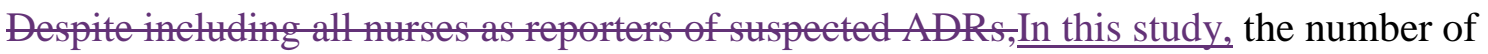
ADR reports froms reported by nurses seemed to decrease in 2010 appeared to decrease compared towith 2005 in this study. The main decrease was observed among nurses working in the school healthcare, where a $50 \%$ reduction occurred. These nurses administer vaccinations within the Swedish childhood vaccination programme_to children in school-and a large part of their reports concern vaccine-related ADRs related to vaceines-[11]. Due to changes in the vaccines included in In October 2003 and 2005, the Swedish Medical Products Agency (MPA) requested issued a letter to-nurses/physicians working in the school healthcare-with a request to report all ADRs, including those listed in the ADR section of the

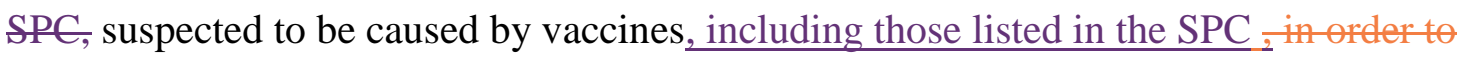
increase the knowledge of these ADRs [21]. The same procedure was performed requested in 
Sweden Sweden and the MPA encouraged nurses/physicians working in the schoøl healthcare to report all ADRs observed related to this vaccine-[21, 22]. These two events might explain the high number of reports from nurses working in the-school healthcare in 2005. In fact, if excluding reports from nurses working in the school healthcare, an increase in reports fromby nurses in this study was indicated observed in $2010(11 \%)$ compared to between-2005-and 2010 in this study_((7\%)-of reports in 2005 vs $11 \%$ in 2010$)$.

The total numberproportion of ADR reports from nurses in this study, 31\% in 2005 and $24 \%$ in 2010, are higher that what was observed in Sweden in 2004 -might appear to be low, $30.6 \%$ in 2005 and 24\% in 2010. These numbers are however higher than 2004 (12\%) and the $90 \mathrm{~s}(2-3 \%)[11]_{2}$. The nurses reporting rate in this study was similar toand in -Italy (23,6\% during 2004-2010) [8] but lower than in Portugal (54\% during 2001-2010) [23]. In Portugal, nurses have been included as reporters since the start of the Portuguese pharmacovigilance system in 1992 and_have therefore_have a longer tradition of reporting ADRs. In aA Swedish survey from 2010 [9], a random sample of 753 nurses was includedperformed on, members fromin -a random sample of nurses who were members in one of two trade unions, the Swedish Association of Health Professionals (engaged 75, 300 Swedish nurses at the time), that engaged 75300 nurses in Sweden at the time. Of the 453 nurses that responded to the survey, 58\% reported that they were aware of their role as reporters of suspected ADRs but only 14\% stated that they had reported an ADR. Nurses' involvement in Pharmacovigilance activities in Sweden could could hence be further encouraged-even further.

The main purpose of spontaneous ADR reporting is to detect previously unknown ADRs and unknown information about known ADRs.Although the number of ADR reportss reported 
by from nurses in this study appeared to decrease during the study period, there appearedseemed to be an increasedin reporting of serious and/or unlabelled reactions.

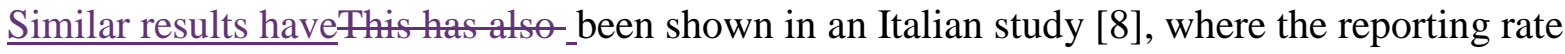
of serious reactions from Italian nurses increased from $13 \%$ in 2004 to $26 \%$ in 2010-[8]. The proportion of serious ADRs in our study is however low compared with a previous Swedish study [11] where 8\% of nurses' reports were assessed as serious in 2003 and 2004. Previous studies $[10,13,24]$ have shown that education has led to increased the reporting of serious and/or unlabelled suspected ADRs by nurses. This might may be due to the fact that because due to that emphasis is put on the importance of reporting serious and unlabelled ADRs is emphasised during thi during these education and training programss education.. In two Swedish studies nurses at departments of internal medicines [13], orthopaedic [13] and geriatric medicine [25] received information on ADRs and on how to report ADRs. During the one year follow up 23 reports were submitted from the departments of internal medicines and orthopaedics of which $74 \%$ were assessed as serious and $20 \%$ as unlabelled [13]. The nurses inFrom the department of geriatric medicine_submitted 18 reports were submitted

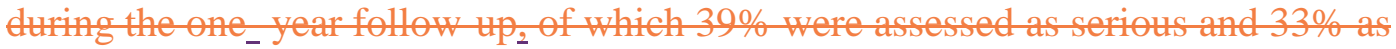
unlabelled [25]. These results show that education in fact may lead to increased reporting of serious and/or unlabelled reactions. In a study from the UK [12] nurses received information on how to report ADRs. During the follow up of 13, 17 and 21 months, 177 reports were submitted and $36 \%$ of the reports submitted by nurses were assessed as serious.

Vaccines have for long constituted the majority of reported drugs from nurses in Sweden [11] as well as in the UK [12]. A closer observation of all serious and/or unlabelled ADRs reported by nurses in this study showed a broadened spectrum of suspected drugs in 2010 compared to 2005, even if vaccines still accounted for the majority of suspected drug 
reactions. causing the serious and/or unlabelled reactions.-In addition to vaccines, nurses' reports on serious ADRs also included-such as anti-bacterials and, anti-epileptics and drugs for treatment of bone disease and obstructive airways. In the study where nursing reporting was introduced in clinical departments [13], neurological, gastrointestinal, psychiatric reactions were most commonly reported.

This study shows that the reporting ofed ADRs byfrom physicians -was not negatively affected by the inclusion of nurses as ADR reports, since appearethe number of ADR reports from physicians increased $\mathrm{d}$ to be higher in 2010 compared to that of 2005 . In a Thus including nurses as reporters of $A D R$ s does not seem to have a negative effect on $A D R$ reporting by physicians. This has also been shown in a reporting in Sweden [13] -where $89 \%$ of the physicians stated that their own willingness to report was not affected by nurses reporting. Moreover, in a Swedishene-survey [26] thea majority of hospital physicians in Sweden reported that they were positive or neutral to nurses reporting. Further studies are however needed to assess the effect on physicians reporting.

The main limitation of this study, however, -is that we were not able to take other factors into consideration other factors that mightay have affected the reporting rate during the study period $_{2}$ such as media attention on specific ADRs. Another limitation was the generalizability of the results to other regions in Sweden and outside of Sweden, since. In this study only ADR reports received by two of six regional pharmacovigilance centres in Sweden havwase been scrutinized. Moreover, we only compared the reporting of suspected ADRs in 2005 and

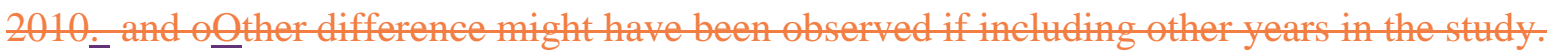




\section{Conclusions}

The overall ADR reporting from nurses was in the same order of magnitude after the inclusion of all nurses as $A D R$ reporters. There was an increase in reports from-other nurses than thøse working in schøøl healtheareprimary care and hospitals, and, there also appeared to be an increase of serious and/or unlabelled ADR reports from nurses in general after the legislative amendment. Most of the nurses nurses',ADR reports that waere classified sere assessed-as serious and/or unlabelled reactions were related to vaccine administrations. Taken together our data suggests that further pro-active measures should be considered in order to involve nurses in the reporting of suspected ADRs.Based on our studies we suggest that fFurther actions should be considered in order to involve nurses more effectively in the reporting of suspected $A D R$.

\section{Acknowledgements}

The authors would like to thank Camilla Rosenlund for assisting with data collection in 2005 and xxxPadraigh D'arcy for the linguistic revision.

\section{Contributors}

AKJ was the principal investigator. IJ, MDB, SAK collected data. SAK drafted the manuscript. All authors contributed to the study design, and interpretation of the results and commented on the draft. All authors had full access to the data. AKJ is the guarantor of the study.

\section{Ethical statement}

All procedures performed were in accordance with the ethical standards of the institutional and/or national research committee and with the Helsinki declaration and its later 
amendments or comparable ethical standards. For this type of study formal consent is not required by law.

\section{Conflict of interest statement:}

The authors declare that they have no conflict of interest. 


\section{References}

1 Hallas, J (1996) Drug related hospital admissions in subspecialities of internal medicine. Danish Medical Bulletin 43:141-155

2 Pouyanne, P, Haramburu F, Imbs JL, Bégaud B (2000) Admissions to hospital caused by adverse drug reactions: Cross sectional incidence study. British Medical Journal $320: 1036$

3 Smith, CC, Bennett PM, Pearce HM, Harrison PI, Reynolds DJM, Aronson JK, Grahame-Smith DG (1996) Adverse drug reactions in a hospital general medical unit meriting notification to the Committee on Safety of Medicines. British Journal of Clinical Pharmacology 42:423-429

4 Stausberg, J, Hasford J (2011) Drug-related admissions and hospital-acquired adverse drug events in Germany: A longitudinal analysis from 2003 to 2007 of ICD-10-coded routine data. BMC Health Services Research 11

von Euler, M, Eliasson E, Öhlen G, Bergman U (2006) Adverse drug reactions causing hospilatization can be monitored from computerized medical records and thereby indicate the quality of drug utilization. Pharmacoepidemiology and Drug Safety $15: 179-184$

6 Hazell, L, Shakir SAW (2006) Under-reporting of adverse drug reactions: A systematic review. Drug Safety 29:385-396

7 Talbot J, Waller P (2004) Stephens' Detection of New Adverse Drug Reactions John wiley \& sons Ltd, the Atrium, Southern Gate, Chichester, West sussex PO19 8SQ, England.

8 Conforti, A, Opri S, D'Incau P, Sottosanti L, Moretti U, Ferrazin F, Leone R (2012) Adverse drug reaction reporting by nurses: Analysis of Italian pharmacovigilance database. Pharmacoepidemiology and Drug Safety 21:597-602 
9 Ekman, E, Petersson G, Tågerud S, Bäckström M (2012) Awareness among nurses about reporting of adverse drug reactions in Sweden. Drug, Healthcare and Patient Safety 4:61-66

10 Hall, M, McCormack P, Arthurs N, Feely J (1995) The spontaneous reporting of adverse drug reactions by nurses. British Journal of Clinical Pharmacology 40:173175

11 Ulfvarson, J, Mejyr S, Bergman U (2007) Nurses are increasingly involved in pharmacogivilance in Sweden. Pharmacoepidemiology and Drug Safety 16:532-537

12 Morrison-Griffiths, S, Pirmohamed M (2000) Specialist nurse reporting of adverse drug reactions. Professional nurse (London, England) 15:300-304

13 Bäckström, M, Ekman E, Mjörndal T (2007) Adverse drug reaction reporting by nurses in Sweden. European Journal of Clinical Pharmacology 63:613-618

14 The adverse drug reaction investigation (2003) http://www.lakemedelsverket.se/Allanyheter/NYHETER-2007/Aven-sjukskoterskor-far-rapporteralakemedelsbiverkningar-/ Last accessed 19 Februray 2015 (In Swedish)

15 Act (LVFS 2001: 12) on regulations on pharmacovigilance, Swedish code of statues [Svensk författningssamling (SFS)]. (2006) (In Swedish)

16 (1972) World health organisation. International drug monitoring: The role of the hospital. Technical report series 498 Geneva, Switzerland

17 (2009) WHO Collaborating Centre for Drug Statistics Methodology Guidelines for ATC classification and DDD assignment

18 (2011) Medical Dictionary for Regulatory Activities. Introductory Guide MedDRA Version 14.0 MSSO-DI-6003-14.0.0 Geneva

19 Edwards, IR, Aronson JK (2000) Adverse drug reactions: Definitions, diagnosis, and management. Lancet 356:1255-1259 
20 Hakkarainen, KM, Gyllensten H, Jonsson AK, Andersson Sundell K, Petzold M, Hagg S (2014) Prevalence, nature and potential preventability of adverse drug events - a population-based medical record study of 4970 adults. Br J Clin Pharmacol 78:170-183 DOI 10.1111/bcp.12314

21 The Medical Products Agency's desire for increased reporting of adverse drug reactions related to vaccines have yielded results (2004) http://www.lakemedelsverket.se/Alla-nyheter/NYHETER---2004/Lakemedelsverketsonskemal-om-okad-rapportering-av-vaccinbiverkningar-har-givit-resultat/ Last accessed February 19th 2015 (In Swedish)

22 Experiences of vaccination in year 4 - adverse drug reaction reporting 2005/2006 (2007) http://www.lakemedelsverket.se/Alla-nyheter/NYHETER-2007/Erfarenheterav-vaccination-i-ak-4--biverkningsrapportering-20052006/ Last accessed February 19th 2015 (In Swedish)

23 Mendes, D, Alves C, Batel Marques F (2014) Nurses' spontaneous reporting of adverse drug reactions: Expert review of routine reports. Journal of Nursing Management 22:322-330

24 Morrison-Griffiths, S, Pirmohamed M (2000) Specialist nurse reporting of adverse drug reactions. Prof Nurse 15:300-304

25 Bäckström, M, Mjörndal T, Dahlqvist R (2002) Spontaneous reporting of adverse drug reactions by nurses. Pharmacoepidemiology and Drug Safety 11:647-650

26 Ekman, E, Bäckstrom M (2009) Attitudes among hospital physicians to the reporting of adverse drug reactions in Sweden. Eur J Clin Pharmacol 65:43-46 DOI $10.1007 / \mathrm{s} 00228-008-0564-9$ 
Table 1. Characteristics of healthcare professionals reporting ADRs in the Southeast and Northern pharmacovigilance region in 2005 and 2010.

\begin{tabular}{|c|c|c|c|c|c|c|}
\hline & \multicolumn{2}{|c|}{ All reporters } & \multicolumn{2}{|c|}{$\begin{array}{l}\text { Reports from the Southeast } \\
\text { pharmacovigilance region }\end{array}$} & \multicolumn{2}{|c|}{$\begin{array}{l}\text { Reports from the Northern } \\
\text { pharmacovigilance region }\end{array}$} \\
\hline & 2005 & 2010 & 2005 & 2010 & 2005 & 2010 \\
\hline & $\begin{array}{l}\text { Number of } \\
\text { reports (\%) } \\
\mathrm{N}=898\end{array}$ & $\begin{array}{c}\text { Number of } \\
\text { reports (\%) } \\
\mathrm{N}=1074\end{array}$ & $\begin{array}{l}\text { Number of } \\
\text { reports }(\%) \\
\mathrm{N}=560\end{array}$ & $\begin{array}{l}\text { Number of } \\
\text { reports }(\%) \\
\mathrm{N}=680\end{array}$ & $\begin{array}{c}\text { Number of } \\
\text { reports }(\%) \\
\mathrm{N}=338\end{array}$ & $\begin{array}{c}\text { Number of } \\
\text { reports (\%) } \\
\mathrm{N}=394\end{array}$ \\
\hline Female reporter $^{\mathrm{s}}$ & $524(58)$ & $641(60)$ & $340(61)$ & 404 (59) & $184(54)$ & $237(60)$ \\
\hline All nurses ${ }^{b}$ & $275(31)$ & $260(24)$ & $208(37)$ & $176(26)$ & $67(20)$ & $84(21)$ \\
\hline $\begin{array}{l}\text { Nurses working in } \\
\text { primary care }\end{array}$ & $57(6)$ & $96(9)$ & $38(7)$ & $68(10)$ & $19(6)$ & $28(7)$ \\
\hline $\begin{array}{c}\text { Nurses working in } \\
\text { hospital }\end{array}$ & $4(0.4)$ & $25(2)$ & $2(0.4)$ & $19(3)$ & $2(1)$ & $6(2)$ \\
\hline $\begin{array}{l}\text { Nurses working in } \\
\text { school healthcare }\end{array}$ & $214(24)$ & $137(13)$ & $168(30)$ & $88(13)$ & $46(14)$ & $49(12)$ \\
\hline All physicians ${ }^{\text {b }}$ & $601(67)$ & $803(75)$ & $342(61)$ & $498(73)$ & $259(77)$ & $305(77)$ \\
\hline $\begin{array}{c}\text { Physicans working } \\
\text { as General } \\
\text { practitioner }\end{array}$ & $207(23)$ & $161(15)$ & $99(18)$ & $84(12)$ & $108(32)$ & $77(20)$ \\
\hline $\begin{array}{l}\text { Physicans working } \\
\text { in Hospital }\end{array}$ & $394(44)$ & $640(60)$ & $243(43)$ & $412(61)$ & $151(45)$ & $228(58)$ \\
\hline Others $^{\mathrm{c}}$ & $22(2)$ & $11(1)$ & $10(2)$ & $6(1)$ & $12(4)$ & $5(1)$ \\
\hline
\end{tabular}

${ }^{a}$ The sex of the reporter was unknown in 0 reports in 2005 and 16 reports in 2010.

b The workplace of the reporter was unknown in 0 reports in 2005 and 2 reports in 2010.

${ }^{c}$ The profession of the reporter were unknown in 5 reports in 2005 and 4 reports in 2010. 
Table 2. Characteristics of the suspected ADRs reported in relation to the profession of the reporter.

\begin{tabular}{|l|c|c|c|c|c|c|c|c|}
\hline & \multicolumn{2}{|c|}{ All reporters } & \multicolumn{2}{c|}{ Nurse } & \multicolumn{2}{c|}{ Physician } & 2010 & 2005 \\
& 2005 & 2010 & 2005 & 2010 & 2005 & 2010 \\
& Number of & Number of & Number of & Number of & Number of & Number of & Number of & Number of \\
& reports (\%) & reports (\%) & reports (\%) & reports (\%) & reports (\%) & reports (\%) & reports (\%) & reports (\%) \\
& $\mathrm{N}=898$ & $\mathrm{~N}=1074$ & $\mathrm{~N}=275$ & $\mathrm{~N}=260$ & $\mathrm{~N}=601$ & $\mathrm{~N}=803$ & $\mathrm{~N}=22$ & $\mathrm{~N}=11$ \\
\hline Serious ADRs & $301(34)$ & $413(39)$ & $7(3)$ & $17(7)$ & $286(48)$ & $393(49)$ & $8(36)$ & $3(27)$ \\
\hline Fatal ADRs & & & & & & & & \\
\hline
\end{tabular}

Abbreviations: ADR, adverse drug reaction; SPC, Summary of Product Characteristics.

a At least one ADR diagnosis was classified as not labelled in the SPC.

${ }^{\mathrm{b}}$ All ADR diagnosis of one case classified as certain, probable and/or possible. 
Table 3. All serious or unlabelled ADRs in relation to the suspected substance reported by nurses in 2005 and 2010.

\begin{tabular}{|c|c|c|}
\hline Year & $\begin{array}{l}\text { (ATC code) } \\
\text { Drug group } \\
\text { (Number of reports) }\end{array}$ & $\begin{array}{l}\text { Reported ADR }{ }^{\mathrm{a}, \mathrm{b}} \\
\text { (Number of reports) }\end{array}$ \\
\hline \multicolumn{3}{|l|}{2005} \\
\hline & (A10) Drugs used in diabetes (1) & Reproductive system and breast disorders $^{\mathrm{c}}(1)$ \\
\hline & $\begin{array}{l}\text { (G03) Sex hormones and } \\
\text { modulators of the genital system (2) }\end{array}$ & $\begin{array}{l}\text { Skin and subcutaneous tissue disorders } \\
\text { c }(1), \text { general disorders and } \\
\text { administration site conditions }^{\mathrm{c}}(1), \text { cardiac disorders }^{\mathrm{c}}(1)\end{array}$ \\
\hline & (J07) Vaccines (14) & 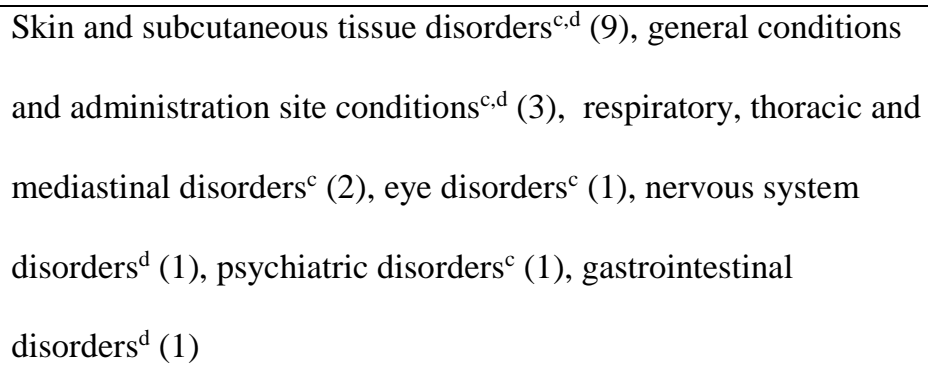 \\
\hline & (N06) Psychoanaleptics (1) & Psychiatric disorders $^{\mathrm{d}}(1)$ \\
\hline \multicolumn{3}{|l|}{2010} \\
\hline & $\begin{array}{l}\text { (A02) Drugs for acid related } \\
\text { disorders (1) }\end{array}$ & General disorders and administration site conditions ${ }^{\mathrm{c}}(1)$ \\
\hline & (C08) Calcium channel blockers (1) & Psychiatric disorders ${ }^{\mathrm{c}}(1)$ \\
\hline & $\begin{array}{l}\text { (C09) Agents acting on the renin- } \\
\text { angiotensin system (1) }\end{array}$ & Respiratory, thoracic and mediastinal disorders ${ }^{\mathrm{c}}(1)$ \\
\hline & (G02) Other gynaecologicals (1) & $\begin{array}{l}\text { Respiratory, thoracic and mediastinal disorders }{ }^{\mathrm{c}}(1), \\
\text { gastrointestinal disorders }^{\mathrm{c}}(1)\end{array}$ \\
\hline & $\begin{array}{l}\text { (G03) Sex hormones and } \\
\text { modulators of the genital system (1) }\end{array}$ & $\begin{array}{l}\text { Psychiatric disorders }^{\mathrm{c}}(1), \text { general disorders and administration } \\
\text { site conditions }{ }^{\mathrm{c}}(1)\end{array}$ \\
\hline & $\begin{array}{l}\text { (H01) Pituitary and hypothalamic } \\
\text { hormones and analogues (1) }\end{array}$ & Nervous system disorders ${ }^{\mathrm{c}}(1)$ \\
\hline & (J01) Antibacterials (2) & $\begin{array}{l}\text { Skin and subcutaneous tissue disorders }{ }^{\mathrm{c}, \mathrm{d}}(1) \text {, general disorders } \\
\text { and administration site conditions }^{\mathrm{d}}(1)\end{array}$ \\
\hline & (J07) Vaccines (36) & General disorders and administration site conditions ${ }^{\mathrm{c}, \mathrm{d}}(24)$, \\
\hline
\end{tabular}




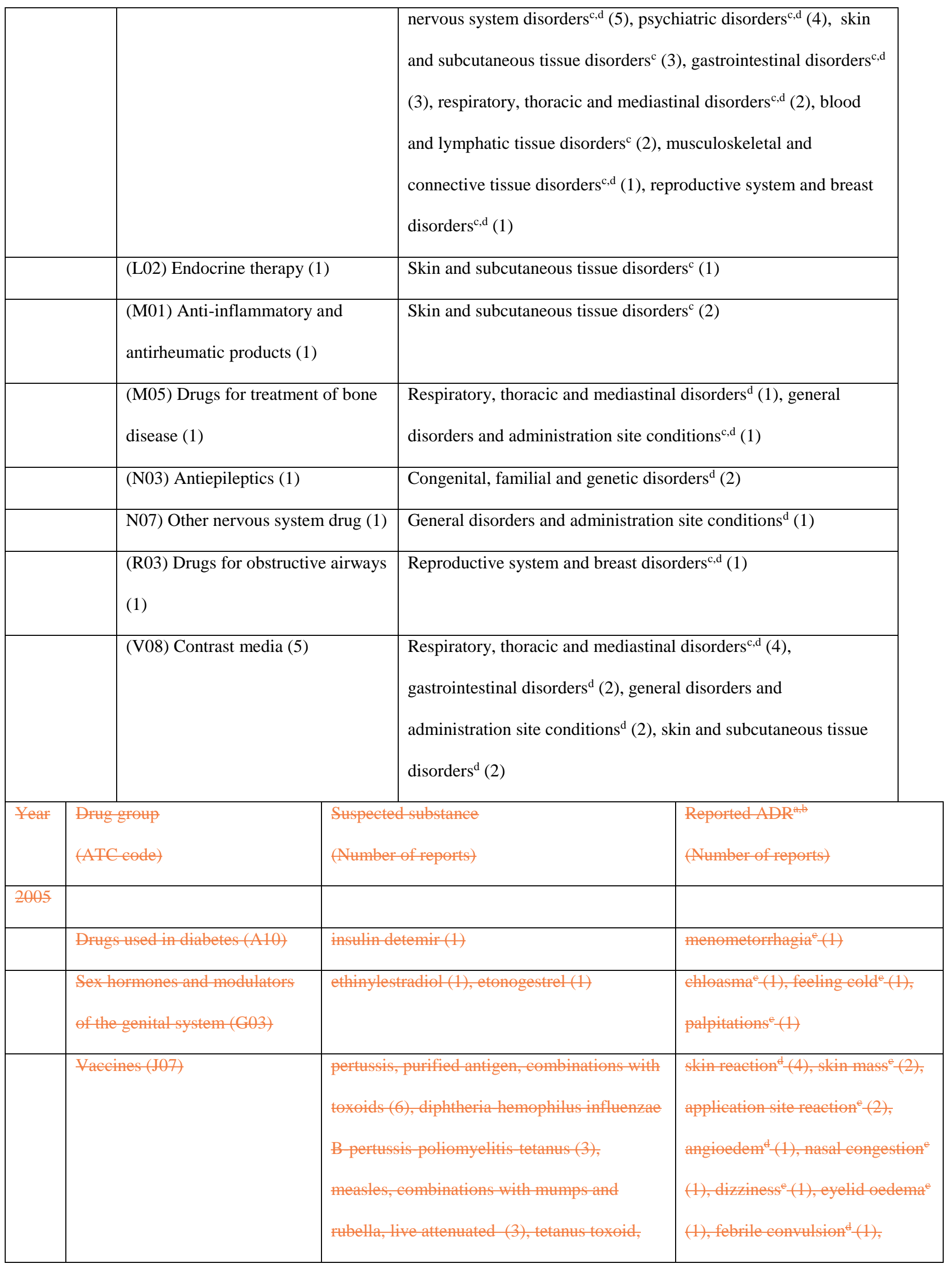




\begin{tabular}{|c|c|c|c|c|}
\hline & & eombinations with diphtheria toxoid (2) & $\begin{array}{l}\text { hypersensitivity }^{\mathrm{d}}(1) \text {, irritabi } \\
\text { (1), nasal pruritus } \\
\text { (1) }(1) \text {, pomiting } \\
\text { (1) }\end{array}$ & $i^{\mathrm{d}}$ \\
\hline & Psychoanaleptics (NO6) & venlafaxine (1) & eompleted suicide ${ }^{\mathrm{d}}(1)$ & \\
\hline \multicolumn{5}{|l|}{2010} \\
\hline & $\begin{array}{l}\text { Drugs for acid related disorders } \\
(\mathrm{A} 02)\end{array}$ & emeprazol (1) & drug ineffective ${ }^{e}(1)$ & \\
\hline & Calcium channel blockers (CO8) & felodipine (1) & depressed mood $(1)$ & \\
\hline & $\begin{array}{l}\text { Agents acting on the renin- } \\
\text { angiotensin system (CO9) }\end{array}$ & candesartan (1) & dyspnoea ${ }^{\mathrm{e}}(1)$ & \\
\hline & Other gynaecologicals (G02) & levonogestrel (1) & dyspnoea ${ }^{e}(1)$, vomiting ${ }^{e}-(1)$ & \\
\hline & $\begin{array}{l}\text { Sex hormones and modulators } \\
\text { of the genital system (G03) }\end{array}$ & etonogestrel (1) & $\begin{array}{l}\text { obsessive thoughts }^{\epsilon}(1) \text {, dect } \\
\text { appetite }^{\epsilon} \text { (1) }\end{array}$ & ased \\
\hline & $\begin{array}{l}\text { Pituitary and hypothalamic } \\
\text { hormones and analogues (H01) }\end{array}$ & exytecin (1) & sensory disturbance ${ }^{e}(1)$ & \\
\hline & Antibacterials (J01) & cefotaxim (1), nitrofurantoin (1) & $\begin{array}{l}\text { erythema multiforme }{ }^{\mathrm{e}, \mathrm{d}}(1), \\
\text { hypersensitivity }^{\mathrm{d}}(1)\end{array}$ & \\
\hline & Vaccines (J07) & $\begin{array}{l}\text { influenza, inactivated, split virus or surface } \\
\text { antigen (13),-diphtheria hemophilus } \\
\text { influenzae B-pertussis-poliomyelitis-tetanus } \\
\text { (6), measles, combinations with mumps and } \\
\text { rubella, live attenuated (6), pertussis, purified } \\
\text { antigen, combinations with toxoids (4), } \\
\text { pneumococcus, purified polysaccharides } \\
\text { antigen conjugated (4), hepatitis B, purified } \\
\text { antigen (1), encephalitis, tick borne, } \\
\text { inactivated, whole virus (1), papillomavirus } \\
\text { (human types } 6,11,16,18) \text { (1) }\end{array}$ & 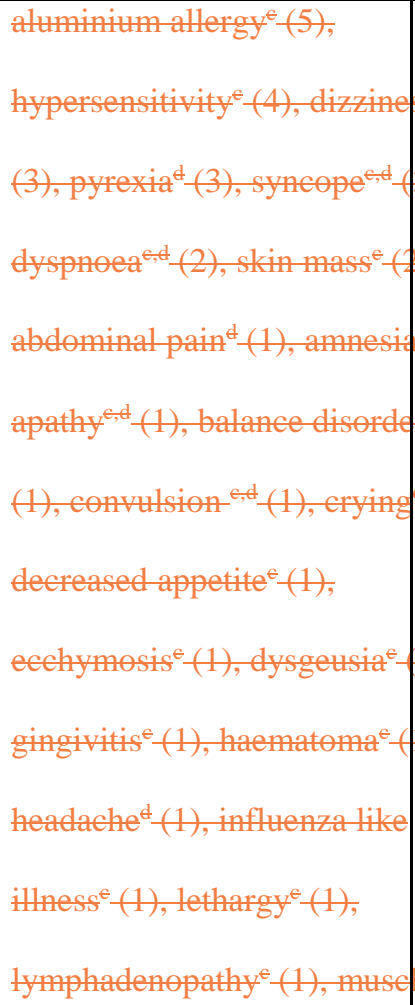 & 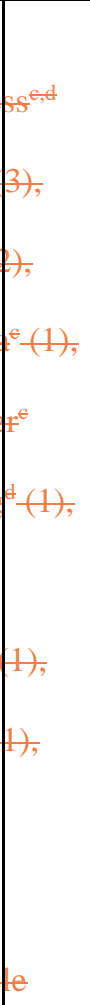 \\
\hline
\end{tabular}




\begin{tabular}{|c|c|c|}
\hline & & 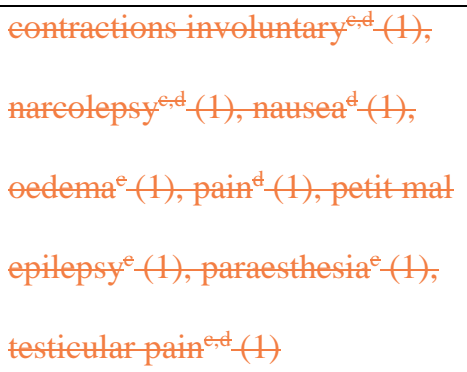 \\
\hline Endocrine therapy (L02) & leuprerelin (1) & skin mass ${ }^{\epsilon}(1)$ \\
\hline $\begin{array}{l}\text { Anti-inflammatory and } \\
\text { antirheumatic products (M01) }\end{array}$ & etoricoxib (1) & $\begin{array}{l}\text { angioeodema }^{\epsilon}(1) \text {, dermatitis } \\
\text { bullos } \\
\text { (1) }\end{array}$ \\
\hline $\begin{array}{l}\text { Drugs for treatment of bone } \\
\text { disease (M05) }\end{array}$ & zoledronic acid (1) & $\begin{array}{l}\text { asthma }^{\mathrm{d}}(1) \text {, influenza like } \\
\text { illness }{ }^{\mathrm{e}, \mathrm{d}} \text { (1) }\end{array}$ \\
\hline Antiepileptics (N03) & topiramat (1) & $\begin{array}{l}\text { eleft palate }^{\mathrm{d}}-(1) \text {, heart disease } \\
\text { congenital }^{\mathrm{d}}-(1)\end{array}$ \\
\hline $\begin{array}{l}\text { Other nervous system drug } \\
\text { (N07) }\end{array}$ & disulfiram (1) & potentiating drug interaction ${ }^{\mathrm{d}}(1)$ \\
\hline $\begin{array}{l}\text { Drugs for obstructive airways } \\
\text { (R03) }\end{array}$ & formoterol (1) & abortion $^{\mathrm{e}, \mathrm{d}}(1)$ \\
\hline Contrast media (V08) & ioversol (3), iomeprol (1), iohexol (1) & 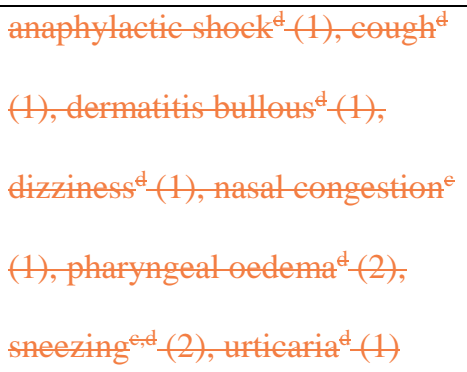 \\
\hline
\end{tabular}

Abbreviations: ADR, adverse drug reaction; ATC, Anatomic Therapeutic Chemical classification system;

MedDRA, Medical Dictionary for Regulatory Activities

${ }^{a}$ One report can contain multiple ADR diagnoses, not all of them within the same system organ class.

${ }^{\mathrm{b}}$ The ADRs are classified according to the System organ class within the MedDRA terminology.

${ }^{c}$ Unlabelled reaction in at least one of the reports

${ }^{\mathrm{d}}$ Serious reaction in at least one of the reports 